\title{
Exploring the Potential for Cross Disciplinary Working with Archives and Records Management
}

\begin{abstract}
This paper explores the potential of cross disciplinary working and collaboration between $\mathrm{HCl}$ and archives and records management. It highlights an emerging interest in personal digital archiving and sees this as a fruitful area for more transformative forms of cross disciplinary working. A study is described in which an attempt is made to expose and actively engage UK based archivists and records managers with a selection of literature and research about personal digital archiving taken from the ACM Digital Library. The aim of the study was to see what, if anything, could be learnt through this process and whether, and in what way, such interaction might engender new insight and innovation. Although little new insight and innovation were so engendered, the study still makes a contribution as a provocation to reflect on cross disciplinary working and its importance for shaping new fields of study such as personal digital archiving.
\end{abstract}

\section{Introduction}

In the report Being Human which tried to imagine $\mathrm{HCl}$ in 2020, emphasis was placed on the need for $\mathrm{HCl}$ to enter into collaboration with other communities and disciplines [3]. Among the other disciplines mentioned in this context were, for example, philosophy and economics, but one that was not mentioned is that of archives and records management. Although this is not entirely surprising, given that archives and records management is a relatively small and unknown discipline, it is the assertion of this paper that its absence should be noticed and should be considered.

Many of the transformations and challenges mentioned in Being Human seem to concern records and archives in some way. For example, the transformation labelled "the end of the ephemeral" is explicitly defined as being about exactly the same questions that have long lain at the heart of archives and records management - questions such as "what it means to record, why we record and what we do with the collected materials" [3]. Then again the case study outlined on "the 'value' of augmenting human memory" is greatly concerned with the management of "archives of data" of the sort that archivists and records managers have been managing for many centuries (albeit in a mainly analogue form) [3]. The two disciplines would seem to have some similar and overlapping interests, but questions remain as to whether and how this overlap can be transformed into something that will generate new insight and innovation. The work in progress being described here is an attempt to explore these questions. 


\section{Related Work}

Moore and Lottridge [6] have reported a framework for defining the different forms of relationships which arise when disciplines work together; with distinctions being drawn in terms of multi-, inter- and trans- disciplinary forms of crossing. These distinctions are used to distinguish both between cross disciplinary working that leads to the formation of new disciplines and specialisms (inter-) and that which leaves the various disciplines in the collaboration relatively untouched (multi-). Also, between a focus on the disciplines (multiand inter-) and one on the "generative potential of the interaction of individuals from different disciplines working together in the context of a specific problem or application" (trans-) [6]. In the more transformative frames of inter- and transdisciplinarity the aim is not to work together to solve a problem defined in terms of one or other of the disciplines involved (e.g. to use techniques and ideas from $\mathrm{HCl}$ to help solve an archives and records management problem or vice versa), but rather to work together to define new problems, perspectives and insights, which may eventually transcend and even eclipse all those originally present.

There are already some examples of successful cross disciplinary working between $\mathrm{HCl}$ and archives and records management, but many of them might best be described as multidisciplinary, rather than the more transformative forms of inter- and transdisciplinary. For example, Crow, Francisco-Revilla, Norris, Shukla and Trace [2] have collaborated to develop an Augmented Processing Table to support the archival process of arrangement. Then again, Bailey and Vidyarthi [1] have suggested that $\mathrm{HCl}$ may be "the missing piece of the records management puzzle" in that it can introduce to records management "a proven, robust and sophisticated way of identifying and meeting the needs of users" which can solve the records management problem of not being "able to fully meet the needs of its users". In both cases, $\mathrm{HCl}$ is brought in as an additional skill set or expertise that is needed to solve a problem or issue within the domain of archives and records management. The level of interaction and its generative potential is still limited within the existing boundaries of the disciplines in question.

Rogers, Scaife and Rizzo [7] have observed that it is "relatively easy" to be multidisciplinary, but that interdisciplinarity is more difficult. They have suggested therefore that it is important to ask "When do you really need interdisciplinarity?" and one of their answers to this question is that it is required when "an existing problem has simply seemed too large for a single discipline to cope with by itself" [7]. It is the assertion of this paper that such a problem is starting to emerge and that, although still ill-defined and amorphous, it is beginning to be seen in the eyes of both $\mathrm{HCl}$ and archives and records management. Those more rooted in $\mathrm{HCl}$ have, as noted above, started to define it as "the end of the ephemeral" [3], but those more rooted in archives and records management tend to frame it more in terms of personal digital archiving. 


\section{Defining the problem}

Archives and records management (ARM) is an applied discipline which has emerged from, but is still intimately connected with, the centuries' old practice of keeping records. Both discipline and practice are marked by a deep sense of moral responsibility for ensuring that a full and representative record of the past is kept to serve; both present needs (e.g. for ensuring accountability and facilitating business, research and other activity), and also, as yet unknown future uses and users. From within ARM, personal digital archiving is an expression of the fact that, as a result of changes in technology, billions of people can and increasingly do record, or have recorded by others, more and more information about their daily lives. Archivists and records mangers are rapidly realizing that the opportunities (for the construction of a fuller and more democratic and accessible record of society) and challenges (in terms of dealing with the scale of this record and with ethical issues around privacy and control over personal data) are not problems they can solve alone.

Hence, two recent attempts to articulate this perspective have explicitly worked to draw in those from other disciplines [4, 5]. For example, Hawkins [4] has edited a multi-authored work entitled Personal Archiving which includes contributions from librarians and archivists, interaction designers and researchers from Microsoft Research and a founding director of the University of Maryland's Human Computer Interaction Laboratory. Then again, Cal Lee's edited work I, Digital: Personal Collections in the Digital Era [5], draws into the arena another partner or source in the form of research into Personal Information Management (PIM) and moves slightly beyond multidisciplinarity into interdisciplinarity in its attempts to translate more fully between ARM and PIM concepts. The work being described here seeks to continue further in the direction of increasing interdisciplinarity by exploring whether and how cross disciplinary working between $\mathrm{ARM}$ and $\mathrm{HCl}$ can generate new insight and innovation in the context of personal digital archiving, or, if you prefer "the end of the ephemeral" [3].

\section{Study Method}

The study undertook its exploration by exposing and actively engaging UK based archivists and records managers to and with a selection of literature and research about personal digital archiving taken from a field with which they would not ordinarily be familiar, to see what, if anything, could be learnt through this process.

The selection to which they were exposed was made in the following manner. On 10 September 2014, a search was carried out on the ACM Digital Library for the terms 'archives' or 'archiving' in the title field only. The search resulted in 364 hits and these were then narrowed down to 30 , on the basis that they needed to deal with subjects, which would be seen and understood as personal digital archiving within ARM. Each of the works in this selection were then individually reviewed and during this process an additional 6 works were added to the selection as a number of articles referenced in the original 30 were also found to be of interest in the same context. All 6 additional articles were however also to be found within the ACM Digital Library. As discussed above the field of personal digital 
archiving is still broadly drawn within ARM and only very vaguely in common with other disciplines. And so, in the absence of, and with the intention of avoiding the drawing of particularly firm boundaries around it, the selection was made on a subjective basis, albeit one informed by a common ARM perspective (the researcher being a long-standing member of that community).

It was felt that the busy professionals who were to be asked to take part in this study, might have difficulty reading 36 articles prior to their participation and so the selection was yet further reduced and summarized as follows. Given the focus on the personal, it was decided that only that research or work which had involved talking, surveying or observing people would be included in the final selection. In this way those participating would be exposed not just to the ideas and insights of a discipline other than their own, but also, at least indirectly, to the opinions and actions of the many different and diverse individuals who made up the study populations of the research in question. This reduced the selection to 11 articles and a summary of these 11 articles was then drawn up.

This summary was placed on the project's website and made available to anyone who was interested. In addition, two initial focus groups (8 participants in total) were organized to test the effectiveness of this approach in engendering cross disciplinary engagement. Invitations to attend the focus groups were sent out through two channels, designed to reach a range of professional archivists and records managers based in the UK. The first was through an email sent out to all the members (around 600) of the Archives and Records Association's (a major UK ARM professional body) Section for Archives and Technology. The second was through posting on a number of professional discussion lists. One of the focus groups was run in conjunction with an established, London based, archives and records management reading group.

Those attending were asked in advance to consider a number of questions, including, for example, do we (as professional archivists/records managers) know this already? If so how do we know it, e.g. in what terms do we talk about the same issue? If not, what is it that we don't know and what can we do with this new-found knowledge? Following the focus groups, notes of the discussions were circulated to the participants for comment. From these notes the following summary was written.

\section{Discussion}

The participants felt it was a worthwhile and interesting exercise to explore work with which they were not previously familiar. They seemed to find it difficult however to articulate what they had learnt from it, rather the sense was that the results being described confirmed what was already known, but did not extend it. One comment was that; we knew this instinctively, but did not have the evidence base for it, implying perhaps that this work provided such a base.

And yet, the fact that those present felt they knew this already, did not mean that they took nothing from the summary. It is just that what they took was more in the form of a prompt 
to reflect back on their own blind spots. For example there was some discussion of how we do not think about this stuff and how for archivists, personal archives have tended to mean the papers of the great of the good, landed families, prime ministers and literary giants rather than ordinary people's collections of stuff. There was also the insight that the work in this area directly engaged with the idea of developing consumer products and services, and that this was not something archivists did.

As well as reflecting on their own blind spots, the participants also saw some in the work being described in the summary. Archives and records management is a single discipline, but it enfolds two slightly different perspectives, increasingly under an umbrella term of recordkeeping. This is important because one thing that was noticeable to the participants in the focus groups was the apparent absence of the records management aspect. Thus, much of the discussion of archiving in a domestic sphere was concerned with photos, social media profiles and what were called by one participant 'nice fluffy things', not with more mundane gas bills, tax returns and bank statements. Those working in ARM see a vital connection between these two aspects, such that they have reservations about both the possibility and the desirability of completely separating either, the two from each other, or the process of both from that of everyday living. It is not a co-incidence that, as we have seen, those involved in archives and records management are also looking out towards the personal information management field.

This last point may also underpin another reservation that was expressed by the participants, namely that the work described in the summary underestimated the complexity involved and gave the impression; both that the right system would solve the problem, and that the right system was the one that did all the hard work in the background so the user did not have to. They questioned both assumptions, some speaking from their experience with trying to implement systems in a corporate records management environment and some talking more theoretically about the fact that what separated an archive from a mass of stuff was an act of conscious selection and evaluation.

Connecting back to the earlier comment about the evidence base, the overarching sense was perhaps that the participants recognized a more empirical perspective which was both more and less practical then their own. More practical with its focus on developing tools and services to assist individuals, less practical in the sense that it did not give them the sort of answers or solutions they needed.

\section{Conclusion}

This study has sought to explore the potential of cross disciplinary working between $\mathrm{HCl}$ and ARM in the area of personal digital archiving. It concludes that those members of the UK ARM profession who participated (all 8 of them) did seem to want to position themselves as seeing things differently to the work that was presented to them in terms of both complexity (a better system or tool for individual use is not the whole answer) and scope (in particular the separate treatment of memory/identity construction - 'nice fluffy things' - and the mundane process of living - being able to pay the gas bill). 
Moving forward though, there is a need to reflect on exactly what the work that was presented to the participants can be taken to represent. Is it representative of $\mathrm{HCl}$ as a discipline or is it rather representative of a certain view of personal digital archiving, which has been found to be limited as described above? If the later, what can we take from the fact that this view was constructed as an amalgam of the researcher's ARM perspective and a body of material/research from $\mathrm{HCl}$ ? Does that make it an interdisciplinary view?

Then again, and more practically, it would be good to run a series of workshops with $\mathrm{HCl}$ practitioners to see what they make of the summary document and the view of personal digital archiving that has been constructed. They too may find it limited in the same or different ways to the archivists and perhaps it is in a consideration of all these limits that cross disciplinary working between $\mathrm{HCl}$ and $\mathrm{ARM}$ will engender some genuine insight and innovation in shaping the field of personal digital archiving.

\section{Acknowledgements}

The author would like to thank all those who participated in the focus groups, including Chris Fryer and James Lappin.

\section{References}

[1] Bailey, S., and Vidyarthi, J. Human-computer interaction: the missing piece of the records management puzzle? Records Management Journal 20, 3 (2010), 279-90.

[2] Crow, J., Francisco-Revilla, L., Norris, A., Shukla, S., and Trace, C. A Unique Arrangement: Organizing Collections for Digital Libraries, Archives, and Repositories. In Proc. TPDL 2012, Springer-Verlag (2012), 335-344.

[3] Harper, R., Rodden, T., Rogers, Y., and Sellen, A. Being Human: Human-Computer Interaction in the Year 2020. Microsoft Research, Cambridge, UK, 2008.

[4] Hawkins, D. (ed.) Personal Archiving: Preserving our Digital Heritage. Information Today Inc., Medford, New Jersey, USA, 2013.

[5] Lee, C. (ed.) I, Digital: Personal Collections in the Digital Era. Society of American Archivists, Chicago, USA, 2011.

[6] Moore, G. and Lottridge, D. Interaction Design in the University: Designing Disciplinary Interactions. In Ext. Abstracts CHI 2010, ACM Press (2010), 2735-44.

[7] Rogers, Y., Scaife, M., and Rizzo, A. Interdisciplinarity: an Emergent or Engineered Process? In Derry, S. J., Schunn, C. D., and Gernsbacher, M.A. (eds) Interdisciplinary Collaboration: An Emerging Cognitive Science, Lawrence Erlbaum Associates, Inc, Mahwah, New Jersey, USA, 2005, 265-86. 